\title{
Patterns of symmetric and asymmetric morphological variation in unicellular green microalgae of the genus Micrasterias (Desmidiales, Viridiplantae)
}

\author{
Jiří NEUSTUPA
}

Department of Botany, Faculty of Science, Charles University of Prague, Benátská 2, CZ-128 01, Prague 2, Czech Republic; e-mail:neustupa@natur.cuni.cz

\begin{abstract}
Morphological symmetry and asymmetry in three clonal populations of Micrasterias cells was decomposed using a new geometric morphometric method specifically developed for shape analysis of complex symmetric structures. Micrasterias cells are symmetric relative to two perpendicular axes of symmetry: a left-right axis and a juvenile-adult axis. Shape variation is decomposed into a component of symmetric variation and other components of asymmetry. Principal component analysis suggested that symmetric variation and juvenile-adult asymmetry were dominant in describing morphological differences among objects in all three datasets. The leftright asymmetric variation among adjacent quadrants of the same semicells was consistently more pronounced than the asymmetric variation with respect to the transversal axis. The strains of Micrasterias radians var. bogoriensis (SVCK 389) and M. radians var. evoluta (SVCK 518) were consistently more variable than the population of M. semiradiata (CAUP K606), with respect to both symmetric and different aspects of asymmetric variation. The shape differences among cell quadrants from opposite semicells were statistically not different from shape differences among cell quadrants from different cells of clonal populations.
\end{abstract}

Key words: asymmetry, desmids, geometric morphometrics, green algae, morphological plasticity, multivariate methods

\section{Introduction}

Asymmetry in biological structures (i.e. deviations from otherwise symmetric morphology) has widely been investigated by utilising morphometric registration of shape. KLINGENBERG \& MCINTYRe (1998) and MARDIA et al. (2000) presented a geometric morphometric-based approach for the analysis of morphological symmetry and asymmetry in left and right sides of bilaterally symmetric organisms that has since been used in numerous studies of symmetry/asymmetry patterns in metazoans (for review, see LEamy \& KLINGENBERG 2005).

Symmetry is an omnipresent feature in protists and different types of complex symmetry are particularly exhibited in freshwater and marine microalgal cells (e.g. green algae) or in inorganic shells (e.g. diatoms). For instance, frustules of many diatoms are typically composed of two bilaterally symmetric halves (e.g. valvar views of Gomphonema or Cymbella spp.) as well as green algae cells (e.g. Tetraedron and Pediastrum spp). Even more frequently, the 2D frontal views of cells are composed of 4 parts that are symmetric according to their $x$ and $y$ axes (biradial symmetry), such as cells of the desmid genus Micrasterias or valvar views of many pennate diatom frustules (Frustulia, Navicula, and Stauroneis spp.). Desmid cells are typically composed of two bilaterally symmetric semicells arranged according to two perpendicular axes of symmetry. Desmids reproduce by mitotic division in the isthmus plane, i.e. in their narrowest central part. The daughter cells then develop their own semicells so that each cell is composed of 2 unequally old, bilaterally symmetric parts. Interestingly, both quadrants of desmid semicells develop simultaneously. Conversely, symmetry of quadrants belonging to opposite semicells relates to diachronic ontogenetic processes. In contrast to multicellular organisms, the respective left and right halves of bilaterally symmetric structures of protists usually cannot be discerned, as the 
anterior and posterior parts of cells do not differ. For example, left or right halves of Micrasterias semicells cannot be distinguished or homologised among different cells in a population. Therefore, geometric morphometric studies of protists typically used symmetrised data acquired by averaging shape information from all symmetric parts of a cell (e.g. Potapova \& Hamilton 2007; Veselá et al. 2009; PoulíčKová et al. 2010), or a semicell (Neustupa \& ŠŤastný 2006; Neustupa et al. 2011). However, components of asymmetric variation were omitted from the analysis (Klingenberg et al. 2002). Therefore, shape differences related to allometry or developmental instabilites could not be investigated. Recently, Savriama \& Klingenberg (2011) developed a morphometric framework for decomposing symmetry and different asymmetric parts of morphological variation. This method, which has been based on the principal component analysis (PCA) of geometric morphometric data (i.e. of the Procrustes tangent coordinates), was used in this study.

The members of the green algal group of desmids (Desmidiales, Zygnematophyceae) represent especially suitable model organisms for investigating patterns of symmetricandasymmetric variation in protists. These presumably unicellular relatives of vascular green plants typically inhabit phytobenthos of acidic freshwater wetlands (Coesel \& Meesters 2007; ŠŤastný 2010). About 6000 morphologically defined desmid taxa were described (Brook 1981; Coesel \& Meesters 2007). Mature cells of desmids are surrounded by a rigid cell wall that fixes the cellular shapes. In addition, intricate cells of many desmid species, characterised by numerous lobes and incisions, represent one of the most complex cellular shapes among eukaryotic microorganisms (BROOK 1981). SAVRIAMA et al. (2010) used decomposition of symmetric and asymmetric variation in a model desmid species - Micrasterias rotata-originating from a single population. They illustrated that almost two-thirds of variation were attributed to the vertical asymmetric component, i.e. to the asymmetric variation taking place between juvenile and adult semicells. Therefore, the authors related this asymmetry type primarily to the processes of cellular growth. Symmetric variation (i.e. differences among individuals) spanned approximately $25 \%$ of the total variation, and other types of asymmetry among quadrants of individual cells were much less important.
Apparent deviations from the symmetric morphological body plan were reported for some desmid species and lineages. Pronounced left-right (horizontal) asymmetry is typical for most of the species belonging to the speciesrich genus Closterium (RŮŽIČKA 1977). TEILING (1957) and Ввоок (1981) illustrated that shape asymmetries between opposite semicells may be the defining taxonomic feature of several taxa, such as Micrasterias sudanensis or Allorgeia incredibilis. At the same time, TeILING (1956, 1957) also illustrated taxa with obvious horizontal or transversal asymmetric deviations from the overall biradial symmetry (e.g. Cosmarium zygomorphicum, C. subgranatum, C. onychonema, or Micrasterias mahabuleshwarensis). ŠKALOUD et al. (2011) reconstructed the phylogenetic history of the generic Micrasterias lineage. This genus is formed by several firmly supported clades that differ by their morphological features. Interestingly, clade $\mathrm{H}$, encompassing M. mahabuleshwarensis, $M$. americana, $M$. hardyi, and M. muricata, is typical by cells with transversally asymmetric arrangement of the polar lobe processes. In addition, clade $\mathrm{C}$, including $M$. rotata, M. fimbriata, M. brachyptera, and $M$. torreyi, characteristically has asymmetric lateral lobules, whereas the cell as a whole still keeps the biradial symmetric body plan. The members of clade A, which includes all 3 taxa investigated in the present study, also share the biradial symmetric pattern of their cells.

This study concentrates on decomposition of symmetric and asymmetric variation in the clonal populations of 3 morphologically distinct taxa of the genus Micrasterias (Figs 1-6). The relative importance of individual asymmetry types among species was compared. In addition, the patterns of symmetry and asymmetry were also decomposed in the pooled data set consisting of cells belonging to all 3 investigated species, to test for differences and the amount of individual variation components among species. This analysis involved separate evaluation of principal components spanning purely symmetric variation and vertical, horizontal, and transversal asymmetric variations. In each of these 4 data sets, species differentiation and the amount of variation of individual species were illustrated. Finally, I asked whether the actual shape distances among individual cellular quadrants (evaluated by the tangent Procrustes distances) differ from the shape distances among quadrants of different cells 
taken from the same population. A large fraction of the variation in geometric morphometric data may often be related to size variation due to allometric effects. In desmids, allometry may especially accentuate shape differences between quadrants from opposite semicells, as the juvenile semicell may be slightly smaller than the adult semicell. Therefore, allometric shape variation was separated by multivariate regression of shape data on the size values of individual quadrants (Klingenberg 1996; Monteiro 1999). Size was evaluated using centroid size measure, i.e. by square root of the sum of squared distances from the landmarks to their centroid (ZeLDitch et al. 2004). Three strains used in this study (SVCK 518 identified as $M$. radians var. evoluta; SVCK 389, M. radians var. bogoriensis; and CAUP K606, M. semiradiata) represent distinct species lineages within the genus (Neustupa et al. 2010; Nemjová et al. 2011; ŠKaloud et al. 2011). Their morphological differences are mostly related to variation in complexity of lobulation (Š́KALOUD et al. 2011). M. semiradiata is a species with the least intricate cells among the members of the genus, but the 2 remaining taxa have more complex morphologies with the deeply divided third-order lobules developed in most cells. Therefore, patterns of species discrimination based on different components of symmetric and asymmetric variation were of interest in these 3 taxa representing morphologically different manifestations of the Micrasterias body plan.

\section{Material and Methods}

The cultures were acquired from 2 public microalgal culture collections (CAUP K606 from Culture Collection of Algae, Charles University in Prague; SVCK 389 and SVCK 518 from Sammlung von Conjugaten-Kulturen, Universität Hamburg). Strains were grown for 4 weeks in $250 \mathrm{ml}$ Erlenmeyer flasks in MES-buffered DY IV liquid medium at $23{ }^{\circ} \mathrm{C}$ and illuminated at $40 \mu \mathrm{mol}$ photons. $\mathrm{m}^{-2} \cdot \mathrm{s}^{-1}$ from 18 $\mathrm{W}$ cool fluorescent tubes (Philips TLD 18W/33), at a light:dark regime of 12:12 h. Quantitative shape analysis was based on geometric morphometric methods (ZeLDitch et al. 2004). Microphotographs were taken on an Olympus BX51 light microscope with Olympus Z5060 digital photographic equipment (Olympus Corporation, Tokyo, Japan). In total, 38 cells were analysed from CAUP K606 and SVCK 389 and 31 cells from SVCK 518. There were 36 landmarks depicted on each cell by using TpsDig ver. 2.16 (RoHLF 2010a) positioned in homologous positions on each of the 4 cellular quadrants (Figs 2, 4, 6). The details of the morphological positions of individual landmarks were described by Neustupa et al. (2008). For the decomposition of symmetry and asymmetry, the method of SAVRiama \& KLINGENBERG (2011) was applied for analysis of structures symmetric relative to two perpendicular axes. In such objects with 4 symmetric parts, there are 4 symmetry transformations resulting in a data set consisting of the original configurations, and the relabelled configurations reflected along the $x-, y-$, and $x+y$ axes (Savriama et al. 2010). Each specimen is thus characterised by 4 configurations, and their average shape is perfectly symmetric (SAVRIAMA \& KLINGENBERG 2011). In this case of Micrasterias cells, an original configuration of landmarks for the entire cell and three transformed copies with an appropriate relabelling of landmarks were used in a new combined dataset: reflected copy about the juvenile-adult axis, reflected copy about the left-right axis, and reflected copy about both axes (equivalent to a rotated copy by $180^{\circ}$ ). The final data sets for symmetry and asymmetry decomposition consisted of $4 \times 38=152$ objects in CAUP K606 and SVCK 389 and $4 \times 31=124$ objects in SVCK 518. Given that the PCs can be unambiguously separated into components of symmetric variation and asymmetry, it is possible to sum up the relative amount of variance for each category of shape variation, as well as to visualize the associated shape changes (Savriama et al. 2010; Savriama \& KLingenberg 2011). Morphological variation of the investigated populations was decomposed into 4 parts (represented by individual PCs) that correspond to symmetric variation and to 3 asymmetric components. Asymmetry along the vertical axis reflected the shape differences between semicells of different age. Asymmetry along the horizontal axis spanned shape differences between left and right cell halves, and transversal asymmetry described shape differences combining asymmetric effects along both vertical and horizontal axes.

A Generalised Procrustes analysis (GPA) that superimposes the new combined dataset with all the original configurations and their transformed relabelled copies by removing differences in position, rotation, and size (Dryden \& MARdia 1998; Zelditch et al. 2004). The TpsSmall ver. 1.20 (RohlF 2003) was used to assess the correlation of Procrustes and tangent space distances to ensure that the amount of shape variation in data sets was small enough to allow subsequent statistical analyses (for details, see e.g. Dryden \& Mardia 1998). As the correlations of Procrustes and the Kendall shape spaces were very high in all the data sets $(r>0.99)$, further morphometric analyses were conducted. PCA was performed on the Procrustes coordinates of all original configurations and their transformed relabelled copies and clearly separated components of symmetric shape variation from multiple components of asymmetry. The most important axes spanning symmetric and asymmetric 
variation in the shape of individual species were illustrated by thin-plate splines in TpsRelw ver. 1.49 (RohlF 2010b). The GPA and PCA were conducted using the package shapes ver. 1.0.9 (DRYDEN \& MARDIA 1998) in $\mathrm{R}$ ver. 2.13.0. (R Development Core Team 2011), and the relative amounts of different asymmetry patterns were computed from individual principal components. PCA separated different categories of shape variation (symmetry and vertical, horizontal and transversal segments of asymmetry). This allowed summing up the amount of variance for each category of shape variation. To assess measurement error, the landmarks in the entire set were digitalised twice. The second digitalisation was conducted about 8 months after the original landmarks' coordinates were acquired. Then, the symmetry/asymmetry decomposition was once again conducted in the individual groups, and the resulting values were compared with those obtained in the previous analyses.

The decomposition of the pooled data set that consisted of all 3 strains was conducted in the same way as indicated above. The scores of the original configurations on individual PC axes, describing symmetric variation and vertical, horizontal, and transversal asymmetric variations, were used for assessing species differences in these components of the total shape variation. The patterns of species differentiation based either on symmetric variation or on different components of asymmetric variation were illustrated by 2D non-metric multidimensional scaling (NMDS) of the PC scores in PAST ver. 2.11. (HAMmER et al. 2001). In NMDS, the data are fitted to two dimensions so that there are no further hidden axes of variation, which makes the resulting ordination plots very informative. NMDS is a numerical technique that iteratively seeks a final ordination solution. As a result, any NMDS ordination is not a unique solution and a subsequent analysis of the same data set may result in a somewhat different ordination pattern. However, for Kruskal's stress values $\leq 0.2$ the ordination patterns are considered stable and they can reliably represent distances among objects in the original multivariate space (Borg \& Groenen 2005). To compare the amounts of variation in different segments of symmetry or asymmetry among species the permutation tests for homogeneity of multivariate dispersions were conducted. The $\mathrm{PC}$ axes describing individual segments of symmetry or asymmetry had been taken separately and variation in scores of individual species on these axes was compared using the function betadisper of the package vegan (OKSANEN et al. 2011) in R ver. 2.13.0. (R Development Core Team 2011).
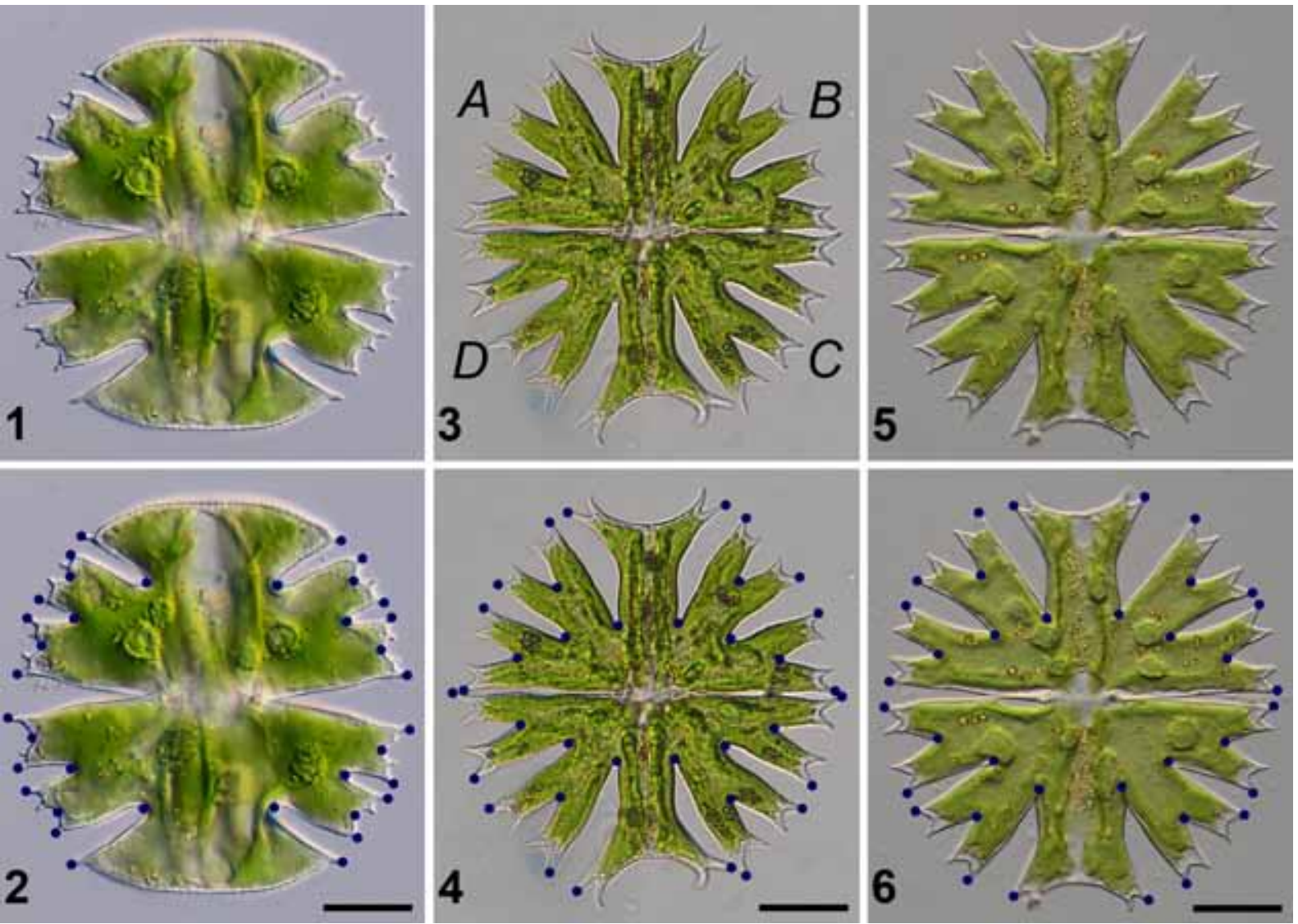

Figs. 1-6. Microphotographs of 3 investigated Micrasterias taxa: $(1,2)$ Micrasterias semiradiata (CAUP K606); (3, 4) Micrasterias radians var. bogoriensis (SVCK 389); and $(5,6)$ Micrasterias radians var. evoluta (SVCK 518). Positions of landmarks $(2,4,6)$ and cellular quadrants A, B, C and D (3) are depicted. Scale bar $20 \mu \mathrm{m}$. 
The tangent Procrustes distances (PD) among individual quadrants were assessed in TpsSmall ver. 1.20. The effect of allometry was separated by multiple regressions of shape data on the centroid size (CS) values of individual quadrants, i.e. on the square root of the sum of squared distances from the landmarks to their centroid (DRYDEN \& MARDIA 1998). Residuals of the regression models were added to the consensus configuration and used for evaluating the allometryfree shape distances among quadrants (KLINGENBERG 1996). Multiple regression was conducted using a routine in $\mathrm{R}$ ver. 2.13.0., and the final values of shape distances were illustrated by box-plots. The mean values of the tangent PDs among within-cell quadrants were compared against the $5 \%$ to $95 \%$ confidence intervals of the random distribution that arose from the 9999 bootstrap repetitions of the original shape distances among all the investigated quadrants.

\section{Results}

The purely symmetric variation and the asymmetric variation with respect to the vertical axis were dominant in all 3 analysed species (Fig. 7). There were slightly higher shares of symmetric variation in SVCK 518 and SVCK 389 strains, but the vertical asymmetric variation spanned the highest proportion in CAUP K606. The symmetric principal components that spanned most of the total variation were - in all species-primarily related to the narrowing of cellular incisions between polar and lateral lobes (Fig. 8). The most important axes that described vertical asymmetric variation were clearly related to allometric changes in CAUP K606 and SVCK 518 , and they were typical by shallowing the incisions and by compressing the polar lobe in the putative juvenile semicell. On the other hand, the most important vertical asymmetric trend of the SVCK 389 population encompassed mainly contraction of the basal parts of semicells, but it did not span shape changes of their polar lobes (Fig. 8). The horizontal and transversal asymmetries were much less important in all 3 species. The PC axes spanning the highest part of the left-right (horizontal) asymmetric variation were uniformly related to lateral deflection of semicells. The most important transversal PC axes in SVCK 518 and SVCK 389 strains spanned variation describing deflection of polar lobes, but in CAUP K606, this axis (PC8) was related to the narrowing of lateral cellular incisions (Fig. 8). Interestingly, horizontal asymmetry (i.e. asymmetry among adjacent quadrants of same semicells) always spanned more

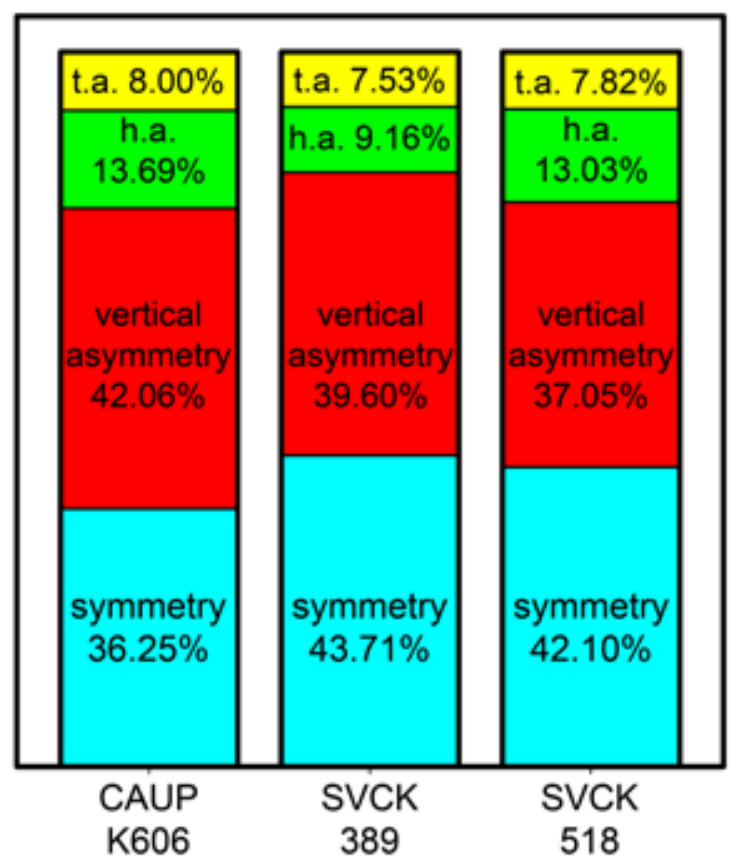

Fig. 7. The bar chart plots illustrating proportions of symmetry and individual types of asymmetry in 3 investigated Micrasterias strains [(h.a.) horizontal asymmetry; (t.a.) transversal asymmetry].

variation than transversal asymmetry (Fig. 7). This difference was relatively negligible in SVCK 389 (1.63\%), but more conspicuous in SVCK 518 and CAUP K606 (5.21\% and 5.69\%, respectively). The repeated digitalisations resulted in virtually identical patterns of symmetry and asymmetry values. The differences in relative proportions of individual symmetry and asymmetry types between the original and repeated digitalisations did not exceed $0.98 \%$ in any of the investigated species. Summing up, the measurement error very probably did not obscure the real patterns of relative symmetry and asymmetry within the investigated data set.

The PCA of the pooled data set consisting of cells from all 3 species allowed separation of principal components spanning individual patterns of symmetric or asymmetric variation. NMDS of the scores of individual objects on symmetric principal components illustrated that the species were clearly separated on the basis of morphological variation, which was symmetric in all 4 cellular quadrants (Fig. 9). The canonical variate analysis (CVA) of symmetric principal component scores strongly discriminated the individual groups (Wilks' $\lambda=0.0001, p<10^{-5}$ ). The cross-validation classification tests illustrated $100 \%$ correct assignment of individual cells into 
Micrasterias semiradiata, CAUP K606

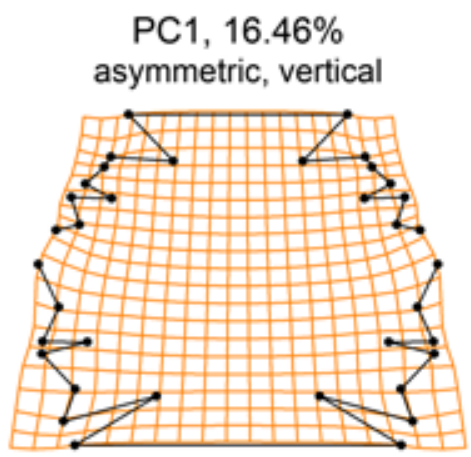

PC2, $14.38 \%$

symmetric

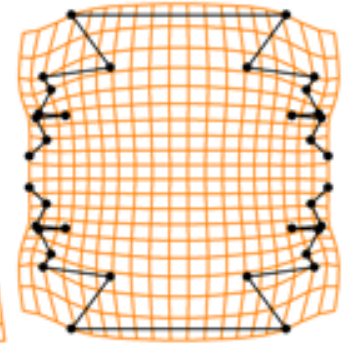

PC5, $8.35 \%$

asymmetric, horizontal

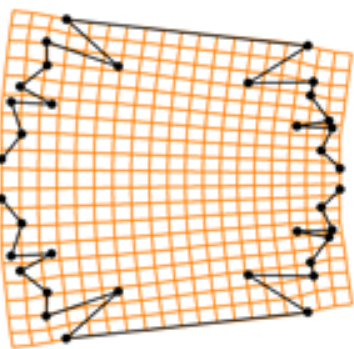

PC8, 2.99\%

asymmetric, transversal

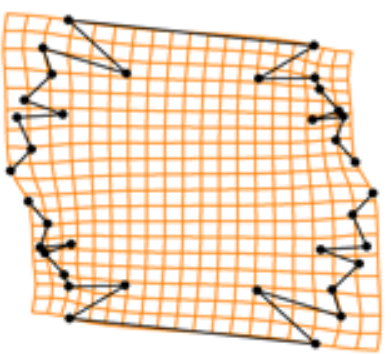

Micrasterias radians var. bogoriensis, SVCK 389

$\mathrm{PC} 1,20.30 \%$
symmetric

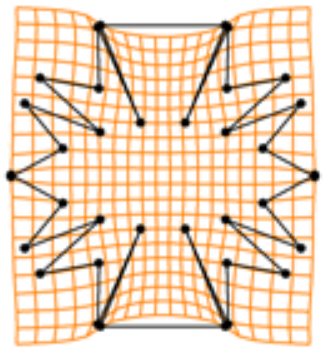

PC2, $16.80 \%$

asymmetric, vertical

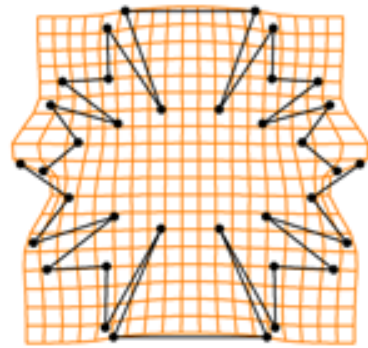

PC8, 3.22\%

asymmetric, horizontal

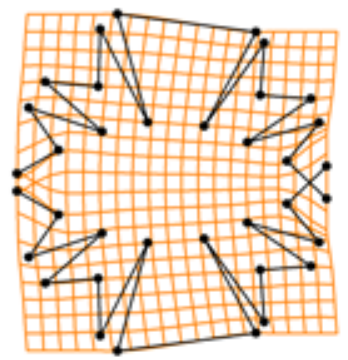

evoluta, SVCK 518

asymmetric, horizontal

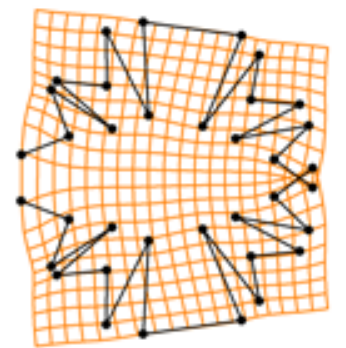

PC10, 2.75\%

asymmetric, transversal

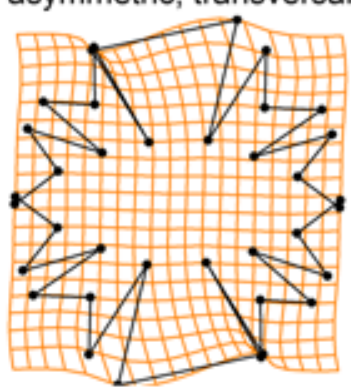

PC8, 3.55\%

asymmetric, transversal

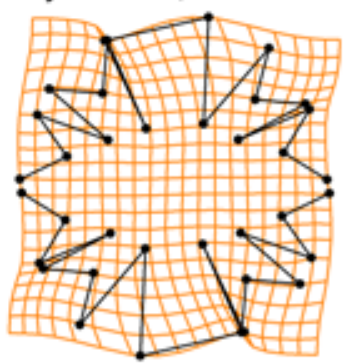

Fig. 8. The thin-plate splines illustrating shape changes spanned by selected PC axes describing different segments of morphological variation of species. Axes spanning the most important components of symmetry and different types of asymmetry were selected. The grid deformations were magnified to allow better visualisation of corresponding changes in the shape of the cells.

their species groups. Conversely, the principal components that spanned asymmetric variation were much less different among the species (Figs 10-12). The CVA of principal components spanning vertical asymmetric variation (asymmetry between semicells) resulted in weak separation of groups (Wilks' $\lambda=0.58, p=0.026$ ). The two-group Hotelling's $\mathrm{T}^{2}$ test illustrated that subtle difference was only detected between mean values of SVCK 389 and CAUP K606 strains (Bonferroni corrected, $p=0.013$ ). The patterns of horizontal asymmetry were not significant among species (Wilks' $\lambda=0.74, p>0.05$ ). Similarly, the transversal asymmetry patterns also did not differ among species (Wilks' $\lambda=0.71, p>0.05$ ).

The amounts of variation described by symmetric or asymmetric components differed among species. The permutation tests for homogeneity of multivariate dispersions based on symmetric PC axes resulted in highly significant differentiation of group dispersions $(p=0.001)$. SVCK 389 cells were most variable, whereas the CAUP K606 had the least variable cells with respect to symmetric morphological variation (Fig. 9). This pattern was very similar in all 3 types of asymmetric variation. The group dispersions were always highly significantly different ( $p=$ 0.001). The population of $M$. semiradiata (CAUP 

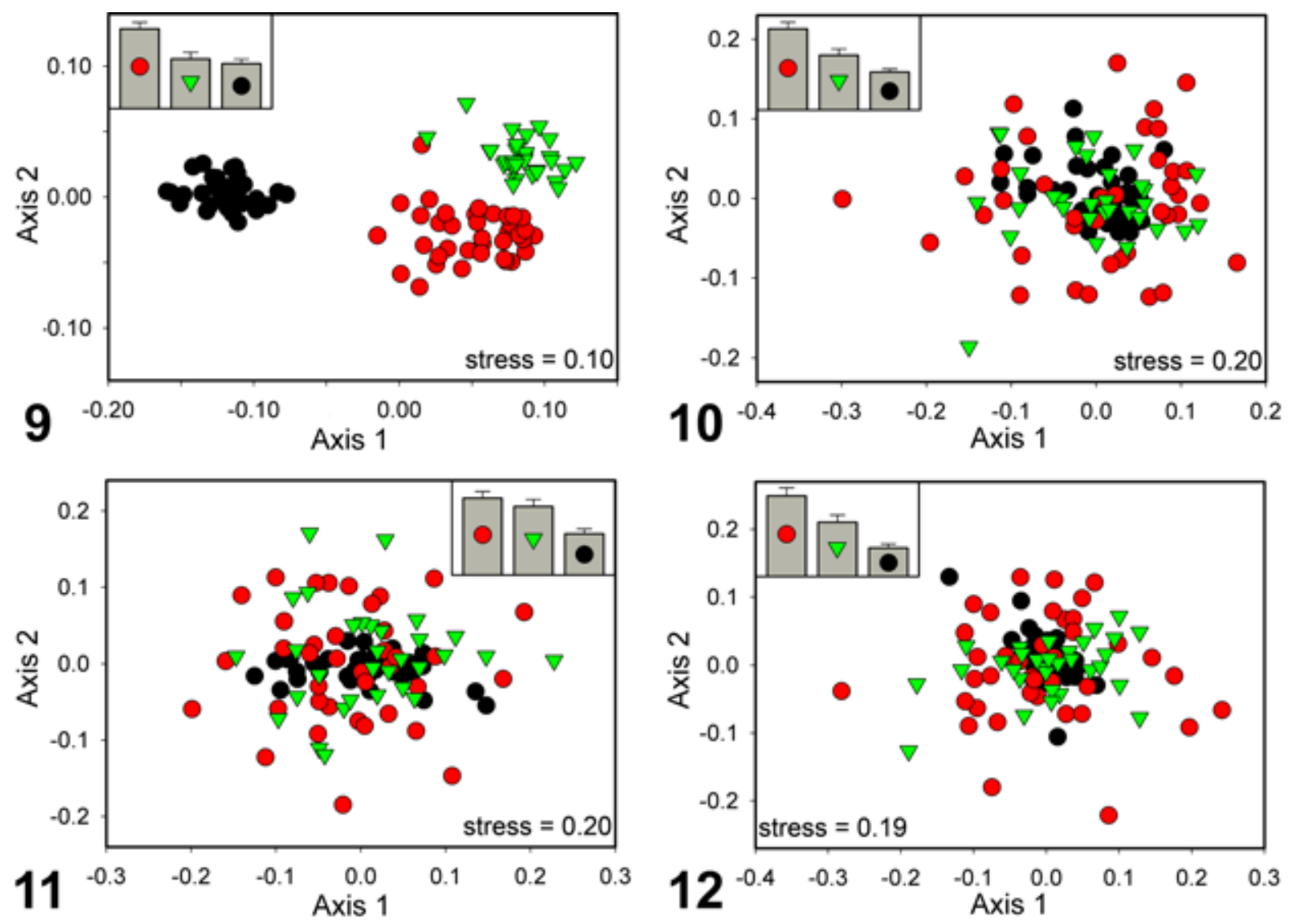

Figs 9-12. Non-metric multidimensional scaling ordination plots representing (9) symmetric morphological variation, (10) asymmetric variation with respect to the vertical (allometric) axis, (11) asymmetric variation with respect to the horizontal (left-right) axis, and (12) asymmetric variation with respect to the transversal axis. The bar chart plots illustrate the amounts of variation in individual species groups [Black circles: Micrasterias semiradiata, CAUP K606; red circles: M. radians var. bogoriensis, SVCK 389; and green triangles: M. radians var. evoluta, SVCK 518].

K606) always had the least asymmetric cells in comparison with the other strains, and M. radians var. bogoriensis (SVCK 389) was consistently the most variable strain with respect to different asymmetry types (Figs 10-12).

The size-controlled shape distances of individual quadrants among different cells within populations were evaluated by tangent PDs of landmark configurations of arbitrarily chosen $\mathrm{A}, \mathrm{B}, \mathrm{C}$, and D quadrants. The shape distances between quadrants within the cells were also measured. Interestingly, the shape distances between 2 quadrants of a same semicell, i.e. between 2 simultaneously developing quadrants, had consistently lower mean PD values than the pairs of quadrants located on opposite semicells, or on different cells of individual clonal populations (Fig. 13). The A-to-B and C-to-D mean shape distances were also consistently below the $5 \%$ to $95 \%$ confidence intervals based on 9999 bootstrap repetitions, creating random sets of tangent PDs corresponding to a number of cells in each population. Conversely, the shape distances of quadrants from opposite semicells of the same cells were not lower than the shape distances of quadrants originating from different cells, as the mean values of all these sets were located within the $5 \%$ to $95 \%$ confidence intervals for the mean shape distances.

\section{Discussion}

In this study, I have applied the general method for geometric morphometric analysis of symmetric shape variation and asymmetry in complex symmetric objects recently introduced by SAVRiama \& Klingenberg (2011) and Savriama et al. (2010). This method was designed for the complete study of any type of symmetry and allows the decomposition of the total shape variation into components of symmetric variation (i.e. differences among individuals) from components of asymmetry (multiple components might occur 

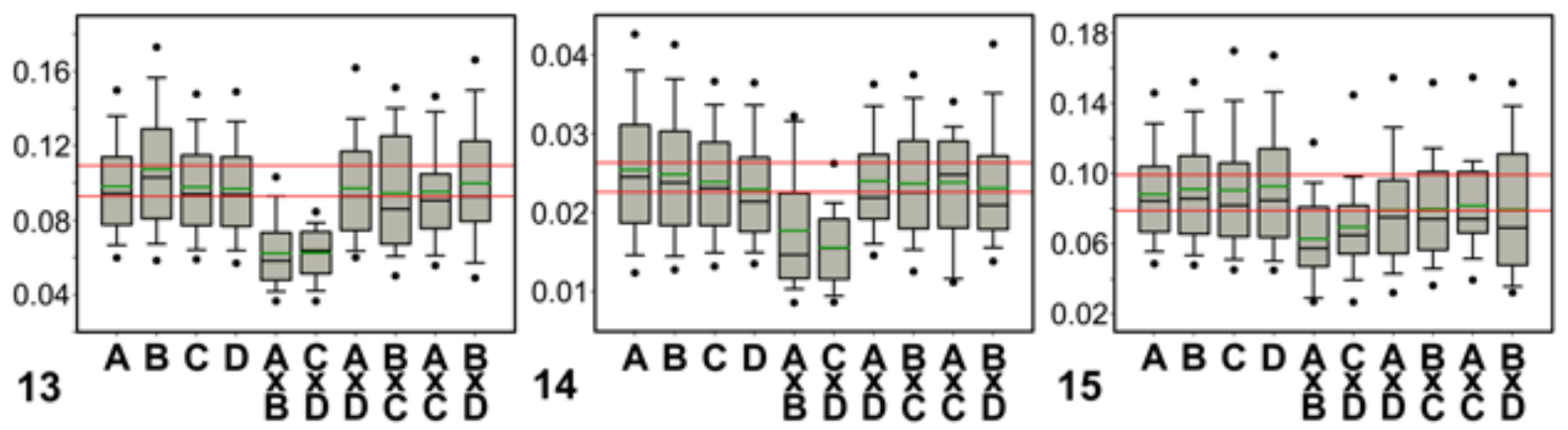

Figs 13-15. Box plots illustrating tangent Procrustes distances among quadrants in (13) Micrasterias semiradiata, CAUP K606; (14) M. radians var. bogoriensis, SVCK 389; and (15) M. radians var. evoluta, SVCK 518. The shape distances among quadrants of different cells (the box plots A to D) and the shape distances between different quadrants from the same cells (the box plots $\mathrm{AxB}, \mathrm{CxD}$, etc.). The quadrants are labelled according to Fig. 3. Green lines correspond to mean values of individual groups. The $5 \%$ to $95 \%$ confidence intervals are depicted by red horizontal lines.

according to the symmetry of the object) (SAVRIAMA et al. 2010; SAVRIAMA \& KLINGENBERG 2011). Using this approach, I have illustrated that symmetric variation did only account for about $35-45 \%$ of the total morphological variation in all 3 data sets (Fig. 7). Conversely, majority of the variation was described by individual patterns of asymmetry among quadrants of Micrasterias cells. Likewise, SAVRIAMA et al. (2010) also illustrated that purely symmetric variation spanned only about $26 \%$ of the total variation in their data set of $M$. rotata cells. Interestingly, similar results that illustrated the dominant role of asymmetric variation in biological objects with multiple symmetric parts were also presented by SAVRIAMA \& KLINGENBERG (2011) in their study of variation in a colonial coral. There are numerous studies dealing with bilateral symmetry/asymmetry patterns of different higher organisms, and symmetric variation has almost always been found dominant over the asymmetric components. SAVRIAMA \& KLINGEnBERG (2011) suggested that a large proportion of morphological asymmetry in colonial corals may be related to their sessile way of life, leaving them differentially exposed to directed environmental factors such as light or water currents. In desmids, however, explanation of this phenomenon may rather rely in their peculiar ontogenesis pattern. Most of the asymmetric variation was contained in vertical asymmetry between 2 unequally old semicells. Therefore, this asymmetry may represent the allometric shape difference between the juvenile and adult semicells (SAVRIAMA et al. 2010), and it may also reflect different environmental conditions during ontogenesis of each of them. Size of the semicells is related to abiotic environmental factors (Neustupa et al.
2008), and SaVRIAma et al. (2010) showed that the ontogenetic and static allometries of Micrasterias semicells are indeed very similar. The asymmetric variation with respect to horizontal and transversal axes describing asymmetries within semicells was considerably less prominent. The ideal body plan of cells of investigated Micrasterias species is symmetric (BRoOK 1981), and these asymmetries must therefore be considered as deviations from the underlying ontogenetic trajectories. Taken together, the horizontal and transversal asymmetry constituted for about $16-21 \%$ of the total variation in individual species. Interestingly, horizontal asymmetry was always more important than asymmetry with respect to the transversal axis. This may imply that the cell quadrants of opposite semicells symmetric along the juvenileadult axis could have statistically more similar shapes than the quadrants symmetric along both juvenile-adult and left-right axes. However, this notion was not fully supported by analysis of the actual tangent PDs among individual quadrants. The consistently lower PDs were only detected among quadrants of the same semicells. It should be noted that shape distances of the quadrants from the opposite semicells of a single cell were statistically not different from quadrants taken from different cells of a single clonal population. Such pattern may only support the notion of Micrasterias cells as compound units that are composed of 2 largely independent morphogenetic halves. Morphological plasticity expressed by the clonal population is then mostly encompassed by the differences between semicells of different age.

Teiling (1956, 1957) and Brook (1981) illustrated that frontal views of desmid cells 
may not only express the ideal symmetric body plans but that species with pronounced vertical, horizontal, or transversal asymmetric patterns also do exist. In this study, I illustrated that the populations of even the seemingly 'totally symmetric' species indeed also include minor aspects of non-allometric, i.e. horizontal or transversal asymmetric variation. However, it may be presumed that desmid species with cells that are apparently asymmetric with respect to horizontal or transversal axes would exhibit a totally different pattern. Phylogenetic origins and mapping of asymmetry patterns on phylogenetic trees in these peculiar desmid taxa such as M. sudanensis (non-allometric vertical asymmetry), Cosmarium zygomorphicum (horizontal asymmetry), or the clade $\mathrm{H}$ of the Micrasterias lineage (transversal asymmetry) would indeed be of much interest. In addition, members of the species-rich desmid family Closteriaceae mostly have cells with pronounced horizontal cell asymmetries, and this character has even been considered one of the key taxonomic features defining this group (RŮŽIČKA 1977; Coesel \& Meesters 2007). Therefore, non-allometric asymmetries apparently played an important role in the morphological evolution of desmids. Comparative molecular and genomic methods may elucidate the genetic basis of the pronounced asymmetries within individual desmid lineages, and morphometric methods presented in this study could provide complete morphological quantification of components of symmetric variation and asymmetry in individual taxa or populations.

Recently, effects of environmental factors on symmetric morphological variation of desmid populations were illustrated (Neustupa et al. 2008; ČERNÁ \& NeUSTUPA 2010). In this context, asymmetric components of shape variation of individual natural populations of desmids should also be tested. Interestingly, there were consistent differences in the amounts of symmetric and asymmetric variation among individual species. The CAUP K606 strain of M. semiradiata had always the least variable cells, and the 2 strains with more complex cells (SVCK 389 and SVCK 518) were more variable. May this pattern be more generally related to cell complexity? May this mean that species of Micrasterias with the most complicated cells (such as M. radiosa or M. sol) would have naturally more variable populations than would other species? In this study, differences in the amounts of symmetric and asymmetric variation among species were similar in symmetric axes as well as in different aspects of asymmetry, but this may not necessarily be the case always, and future studies should incorporate multiple species of the Micrasterias lineage and look for differences in the amounts of asymmetry in relation to environmental or phylogenetic data. Enhanced morphological plasticity and asymmetry values have also been linked to changes in ploidy levels and in the total nuclear DNA contents (ANDERSEN et al. 2006). The protocols for quantification of DNA contents in freshwater microalgal groups (including desmids) have recently been published (Mazaloví et al. 2011), and the genome size data could therefore be related to symmetry/asymmetry levels of individual populations.

The asymmetry analyses in protists significantly lag behind other fields of organismal biology. However, the methodological framework presented by SAVRIAMA et al. (2010) and SAVRIAMA \& Klingenberg (2011), and used in this study, should open up a new promising area of research in this rich, but almost unexplored, field of phycology and morphometrics.

\section{Acknowledgements}

This study was supported by the Czech Science Foundation grant no. 206/09/0906. The author thanks the anonymous reviewer for the invaluable recommendations that led me to the improvements of the manuscript. The Editage proofreading service is also thanked for the language and style corrections.

\section{References}

Andersen, D.H.; Pertoldi, C.; Loeschcke, V. \& Scali, V. (2006): Developmental instability, hybridization and heterozygosity in stick insects of the genus Bacillus (Insecta; Phasmatodea) with different modes of reproduction. - Biological Journal of the Linnean Society 87: 249-259.

Borg, I. \& Groenen, P. (2005). Modern Multidimensional Scaling: theory and applications. -496 pp., Springer, New York.

Brook, A.J. (1981): The biology of desmids. - 276 pp., Blackwell, Oxford.

Coesel, P.F.M. \& Meesters, J. (2007): Desmids of the Lowlands. - 352 pp., KNNV Publishing, Zeist.

ČErnÁ, K. \& Neustupa, J. (2010): The pH-related morphological variations of two acidophilic species of Desmidiales (Viridiplantae) isolated from a lowland peat bog, Czech Republic. Aquatic Ecology 44: 409-419.

Dryden, I.L. \& MARdiA, K.V. (1998): Statistical shape 
analysis. - 376 pp., John Wiley \& Sons, New York.

HAMmer, Ø.; HARPER, D.A.T. \& RYAN, P.D. (2001): PAST: Paleontological statistics software package for education and data analysis. Palaeontologia Electronica 4: 1-9.

KlingenBerG, C.P. (1996): Multivariate allometry. In: Marcus, L.F.; Corti, M.; Loy, A.; NAYlor, G.J.P. \& SlicE, D.E. (eds.): Advances in Morphometrics. - pp. 531-551, Plenum Press, New York.

Klingenberg, C.P. \& McIntyre, G.S. (1998): Geometric morphometrics of developmental instability: analyzing patterns of fluctuating asymmetry with Procrustes methods. - Evolution 52: 1363-1375.

KlingenberG, C.P.; Barluenga, M. \& Meyer, A. (2002): Shape analysis of symmetric structures: quantifying variation among individuals and asymmetry. - Evolution 56: 1909-1920.

LeAmy, L.J. \& KLIngenberG, C.P. (2005): The genetics and evolution of fluctuating asymmetry. Annual Reviews of Ecology and Systematics 36: $1-21$.

Mardia, K.V.; Bookstein, F.L. \& Moreton, I.J. (2000): Statistical assessment of bilateral symmetry of shapes.- Biometrika. 87: 285-300.

Mazalová, P.; ŠArhanovÁ, P.; OndŘEJ, V. \& PoulíčKovÁ, A. (2011): Quantification of DNA content in freshwater microalgae using flow cytometry: a modified protocol for selected green microalgae. - Fottea 11: 317-328.

Monteiro, L.R. (1999): Multivariate regression models and geometric morphometrics: the search for causal factors in the analysis of shape. Systematic Biology 48: 192-199.

Nemuová, K.; Neustupa, J.; ŠŤAstnÝ, J.; ŠKaloud, P. \& Veselá, J. (2011): Species concept and morphological differentiation of strains traditionally assigned to Micrasterias truncata. - Phycological Research 59: 208-220.

Neustupa, J. \& ŠŤAstnÝ, J. (2006): The geometric morphometric study of Central European species of the genus Micrasterias (Zygnematophyceae, Viridiplantae). - Preslia 78: 253-263.

Neustupa, J.; ŠŤAstnÝ, J. \& Hodač, J. (2008): Temperature-related phenotypic plasticity in the green microalga Micrasterias rotata. Aquatic Microbial Ecology 51: 77-86.

Neustupa, J.; ŠKaloud, P. \& ŠŤAstnÝ, J. (2010): The molecular phylogenetic and geometric morphometric evaluation of Micrasterias crux-melitensis/M. radians species complex. Journal of Phycology 46: 703-714.

Neustupa, J.; ŠŤastný, J.; Nemjová, K.; Mazalová, P.; Goodyer, E.; PoulíčKovÁ, A. \& ŠKaloud, P. (2011): A novel, combined approach to assessing species delimitation and biogeography within the well-known desmid species Micrasterias fimbriata and $M$. rotata (Desmidiales, Streptophyta). - Hydrobiologia 667: 223-239.

Oksanen, J.; Blanchet, F.G.; Kindt, R.; Legendre, P.; Minchin, P.R.; O’Hara, R.B.; Simpson, G.L.; Solymos, P.; Stevens, M.H.H. \& Wagner, H. (2011): Vegan: community ecology package. - R Foundation for Statistical Computing, Vienna.

Palmer, A.R. \& Strobeck, C. (1986): Fluctuating asymmetry: measurement, analysis, patterns. - Annual Reviews of Ecology and Systematics 17: 391-421.

Potapova, M. \& Hamilton, P.B. (2007): Morphological and ecological variation within the Achnanthidium minutissimum (Bacillariophyceae) species complex. - Journal of Phycology 43: 561-575.

PoulíčKová, A.; Veselá, J.; Neustupa, J. \& ŠKalOUD, P. (2010): Pseudocryptic diversity versus cosmopolitanism in diatoms: a case study on Navicula cryptocephala Kütz. (Bacillariophyceae) and morphologically similar taxa. - Protist 161: 353-369.

R Development Core Team (2011): R: A language and environment for statistical computing. $-\mathrm{R}$ Foundation for Statistical Computing, Vienna.

Rohlf, F.J. (2003): TpsSmall, ver. 1. 20. - Department of Ecology and Evolution, State University New York at Stony Brook, New York.

Rohlf, F.J. (2010a): TpsDig, ver. 2. 16. - Department of Ecology and Evolution, State University New York at Stony Brook, New York.

Rohlf, F.J. (2010b): TpsRelw, ver. 1. 49. - Department of Ecology and Evolution, State University New York at Stony Brook, New York.

RŮŽıčKA, J. (1977): Die Desmidiaceen Mitteleuropas, Band 1, 1. Lieferung. - 291 pp., Schweizerbart, Stuttgart.

Savriama, Y.; Neustupa, J. \& Klingenberg, C.P. (2010): Geometric morphometrics of symmetry and allometry in Micrasterias rotata (Zygnematophyceae, Viridiplantae). - Nova Hedwigia Beihefte 136: 43-54.

Savriama, Y. \& Klingenberg, C.P. (2011): Beyond bilateral symmetry: geometric morphometric methods for any type of symmetry. - BMC Evolutionary Biology 11: 280.

Škaloud, P.; Nemuová, K.; Veselá, J.; Černá, K. \& Neustupa, J. (2011): A multilocus phylogeny of the desmid genus Micrasterias (Streptophyta): evidence for the accelerated rate ofmorphological evolution in protists. - Molecular Phylogenetics and Evolution 61: 933-943.

ŠŤAstnÝ， J. (2010): Desmids (Conjugatophyceae, Viridiplantae) from the Czech Republic; new and rare taxa, distribution, ecology. - Fottea 10: $1-74$. 
Teiling, E. (1956): On the variation of Micrasterias mahabuleshwarensis f. Wallichii. - Botaniska Notiser 109: 260-274.

TeILING, E. (1957): Morphological investigations of asymmetry in desmids. - Botaniska Notiser 110: 49-82.

Veselá, J.; Neustupa, J.; Pichrtová, M. \& PoulíčKovÁ, A. (2009): Morphometric study of Navicula morphospecies (Baccilariophyta) with respect to diatom life cycle. - Fottea 9: 307-316.

Zelditch, M.L.; Swiderski, D.L.; Sheets, D.H. \& FINK, W.L. (2004): Geometric morphometrics for biologists: a primer. - 452 pp., Elsevier Academic Press, London.

(C) Czech Phycological Society (2013)

Received May 17, 2012

Accepted June 29, 2012 